\title{
Optimized heart rate for 320-row cardiac CT can be feasibly predicted from prescan parameters
}

\author{
Eriko Maeda ${ }^{1 *}$, Nobuo Tomizawa ${ }^{2}$, Kodai Yamamoto ${ }^{3}$, Shigeaki Kanno ${ }^{1}$, Masaaki Akahane ${ }^{4}$, Kenji Ino $^{5}$, \\ Masae Uehara ${ }^{6}$, Aiko Sakamoto ${ }^{6}$, Toshiaki Semboku' ${ }^{7}$, Rumiko Torigoe ${ }^{8}$ and Kuni Ohtomo ${ }^{1}$
}

\section{*Correspondence:}

emaeda-tky@umin.ac.jp

${ }^{1}$ Department of Radiology, Graduate School of Medicine, University of Tokyo

Bunkyo-ku, 7-3-1 Hongo,

Tokyo 113-8655, Japan Full list of author information is available at the end of the article

\begin{abstract}
To evaluate the degree of heart rate (HR) changes at rest (HRrest), during breath hold (HRtest), and during cardiac CT examinations (HRscan) in a large group of patients, and to derive and asses the feasibility of a predictive formula for HRscan. HRrest, HRtest, and HRscan were retrospectively compared in a total of 563 consecutive patients who underwent 320-row cardiac CT. Multiple regression analysis was performed to derive predictive formulae for HRscan in the entire study population and, in each group of patients with decreased (Dec) or increased (Inc) HR during breath hold. The predictive formula was evaluated as accurate when less than $5 \%$ of the actual HRscan exceeded the predicted HRscan by \pm 5 beats per minute $(\mathrm{bpm})$. The average values of the HRtest $(65.3 \pm 12.0 \mathrm{bpm})$ and HRscan $(63.7 \pm 11.9 \mathrm{bpm})$ significantly decreased from those of the HRrest $(68.4 \pm 11.9 \mathrm{bpm})(\mathrm{p}<0.0001)$. The predictive formula $($ HRscan $=3.601+0.113$ HRrest +0.8 HRtest $)$ was determined to be accurate only in Group Dec. The HRtest significantly decreased from the HRrest, and the HRscan significantly decreased from the HRtest. An accurate predictive formula for HRscan could be built only for Group Dec.
\end{abstract}

Keywords: Heart rate, 320-detector row CT, Breath hold, Contrast material

\section{Background}

Cardiac computed tomography $(\mathrm{CT})$ has long been performed with single-source, 64-row scanners or less. Scanning the whole heart requires 6-10 heartbeats, or even more when scanners have fewer rows of detectors. With the advent of 320- and 256-detector row CT and dual-source 64-row CT with Flash mode, it has become possible to perform most adult cardiac CT scans in 1-3 heartbeats. Using 320-row CT, patients with heart rates (HR) lower than 75 beats per minute (bpm) can be scanned with one beat, with some adjustments in their acquisition windows based on the HR. In particular, the acquisition window should be widened to scan the systolic phase as well as the diastolic phase, when the HR is predicted to be relatively fast. In contrast, when the HR during the actual scan is lower than expected, the patient would be exposed to unnecessary radiation during systolic scanning. In this regard, prediction of the scan HR is necessary for patients with low HR, particularly if between 65 and $75 \mathrm{bpm}$. For high

(c) 2015 Maeda et al. This article is distributed under the terms of the Creative Commons Attribution 4.0 International License (http:// creativecommons.org/licenses/by/4.0/, which permits unrestricted use, distribution, and reproduction in any medium, provided you give appropriate credit to the original author(s) and the source, provide a link to the Creative Commons license, and indicate if changes were made. 
HR patients, multi-segment reconstruction may be used to improve temporal resolution (Tomizawa et al. 2013). In multi-segment reconstruction, accurate prediction of HR is necessary to determine the number of scans (i.e., heartbeats) and the time of the gantry rotation, both of which affect temporal resolution (Halliburton et al. 2003; Herzog et al. 2007). Therefore, HR prediction before cardiac CT scan is crucial for both low and high HR patients.

Past studies on changes in HR during breath holding and contrast injection during cardiac CT are small, and gave controversial results. None of these studies involved 320row cardiac CT (Zhang et al. 2008; Horiguchi et al. 2011; Christensen et al. 2011; Becker et al. 2011). We hypothesized that scan HR (HRscan) can be predicted from pre-scan parameters, such as HR at rest (HRrest) and during breath hold (HRtest).

\section{Methods}

Patients

This study was approved by the institutional review board, and was performed in accordance with the ethical standards laid down in the 1964 Declaration of Helsinki and its later amendments. The requirement for informed consent to participate in this study was waived, because of the retrospective design. The patients' records and information were made anonymous before starting the analysis.

The records of 791 consecutive patients (470 men, 321 women; mean age $65.5 \pm 13.9$ years, range 8-94 years) who underwent cardiac CT angiography from August 2011 to July 2013 were retrospectively reviewed. The patients were suspected of having coronary artery disease, had a history of myocardial infarction, or had a complex cardiac anomaly. The exclusion criteria were arrhythmia, such as atrial fibrillation and flutter $(n=43)$, premature ventricular contraction during HR recording $(n=16)$, premature atrial contraction during HR recording $(n=4)$, complete left bundle branch block $(\mathrm{n}=4)$, complete right bundle branch block $(\mathrm{n}=1)$, proxysmal supraventricular tachycardia $(\mathrm{n}=1)$, sick sinus syndrome $(\mathrm{n}=1)$, and sustained ventricular tachycardia $(\mathrm{n}=1)$; presence of pacemakers $(\mathrm{n}=7)$; wide-volume scanning in patients who underwent coronary artery bypass surgery $(\mathrm{n}=88)$; expiratory scanning for ablation planning $(n=9)$; irregular protocol for concurrent evaluation of the pulmonary artery or right ventricle $(n=8)$; pediatric patients $(n=2)$; and inaccurate ECG-recording $(n=43)$.

The final study group included 563 patients (311 men, 252 women; mean age $65.2 \pm 12.9$ years, age range $18-94$ years; body weight $61.3 \pm 14.4 \mathrm{~kg}$, range $32-142 \mathrm{~kg}$ ). Medications that could possibly influence HRs were beta blockers in 290 patients (51.5\%), digitalis derivatives in 110 patients (19.5\%), Calcium channel blockers in 86 patients $(15.3 \%)$, nifedipine in 21 patients $(3.7 \%)$, anti-arrhythmcs in seven patients (1.2\%), and alpha-blockers in three patients (0.5\%).

\section{CT data acquisition}

All examinations were performed by 320-detector CT scanner (Aquilion ONE Vision Edition: Toshiba, Tochigi, Japan) with prospective ECG gating axial scans.

The scanning parameters were as follows: detector configuration, $320 \times 0.5 \mathrm{~mm}$; gantry rotation time, $275,300,320$ or $350 \mathrm{~ms}$ depending on breath hold HR; tube potential, $120 \mathrm{kV}$; and tube current, from at 250 to $760 \mathrm{~mA}$ depending on body habitus. 
Acquisition window and number of scans were determined based on the experience of attending radiologists (EM, NT, KY, and SK). Patients received $22.2 \mathrm{mgI} / \mathrm{kg}$ of Iopamidol $370 \mathrm{mgI} / \mathrm{mL}$ (Iopamiron 370: Bayer, Osaka, Japan); the mean volume administered was $45.7 \pm 10.4 \mathrm{~mL}$ (range, $25-96 \mathrm{~mL}$ ) over $14 \mathrm{~s}$. Bolus tracking was performed using thresholds of $100(\mathrm{HU})$ in the left ventricle and $260 \mathrm{HU}$ in the descending aorta. Patients were assigned to breathe in and hold their breaths after the first threshold. The scan was immediately started after the second threshold.

As a baseline medication, oral $\beta$-blocker was administered to 116 patients. For 173 outpatients with HRs higher than 75 bpm, 20-40 mg of metoprolol (Lopresor: Novartis, Tokyo, Japan), was administered. The patients were instructed to take the medicines $2 \mathrm{~h}$ prior to the examination. In 2013, we started to use an intravenous $\beta$-blocker, landiolol at $0.125 \mathrm{mg} / \mathrm{kg}$ (Corebeta; Ono Pharmaceutical, Osaka, Japan) for patients with HRs higher than $75 \mathrm{bpm}$. Eighteen patients received injection before the test breath hold, and were scanned 4-7 min after injection. Before 2013, no additional $\beta$-blocker was used when the HR was higher than $75 \mathrm{bpm}$ at the time of the examination. No patients who were administered $\beta$-blockers had contraindications, such as hypotension, more than grade II atrioventricular block, severe pulmonary hypertension causing right-sided cardiac failure, severe cardiac failure, and allergy to $\beta$-blockers. There were no side effects from $\beta$-blockers recorded. All patients received $2.5 \mathrm{mg}$ sublingual isosorbide dinitrate (Nitorol; Eisai, Tokyo, Japan) before imaging. No nitrates were administered to patients with contraindications, such as severe hypotension, closed angle glaucoma, and allergy to nitrates.

\section{Acquisition of heart rate}

HR was recorded in terms of RR interval on ECG (IVY Model 3000; Chronos, Chiba, Japan). Mean HR during free breathing for $10 \mathrm{~s}$ (HRrest) was immediately recorded prior to giving instructions for the test breath hold; the actual test breath hold lasted for $10 \mathrm{~s}$. HRtest was defined as the average HR of four beats, with the first beat designated as the one occurring at $5 \mathrm{~s}$ of the test breath hold. HRscan was defined as the average HR of four consecutive beats, with the second beat corresponding to the first CT cardio angiogram scan (Fig. 1).

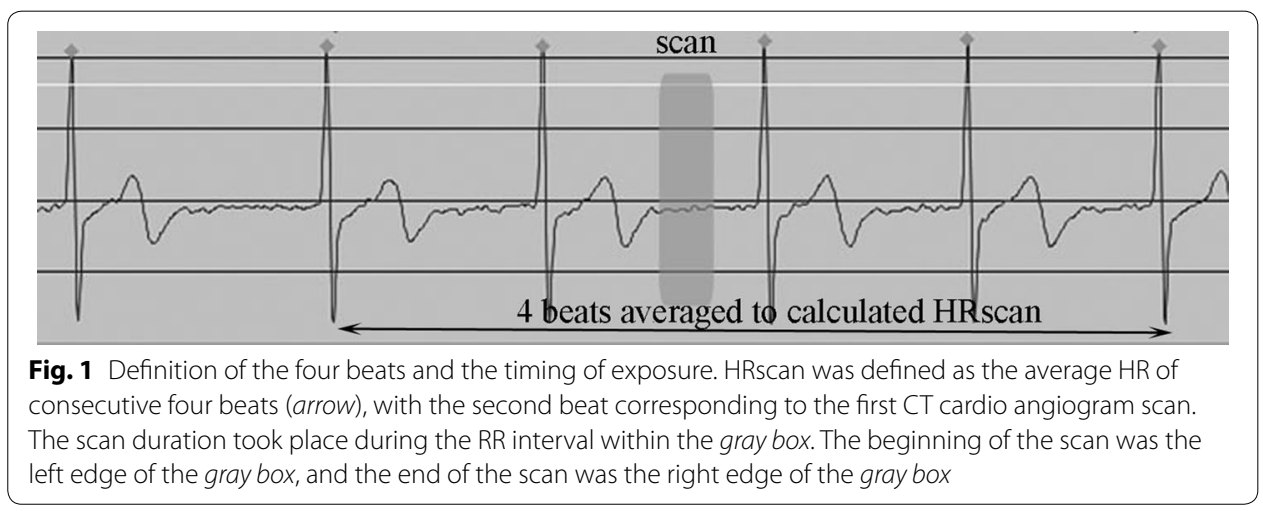




\section{Statistical analysis}

All statistical analyses were performed using JMP Pro software (version 10.0.2; SAS, Cary, NC). Quantitative variables were expressed as mean \pm standard deviation.

The differences in HRrest, HRtest, and HRscan were determined by the Bland-Altman method and were analyzed in the entire population as well as in the groups of patients in whom the HRtest decreased from the HRrest (Group Dec) and those in whom the HR test increased from the HRrest (Group Inc). This analysis based on groups was performed to determine whether the behavior of HR during breath hold was related to the behavior of HR after contrast injection; for this purpose, multiple regression analysis was performed after extracting patients in whom the HRtest decreased from the HRrest. The ratios of changes in HRscan in both groups were analyzed using Fisher's exact test.

Multiple regression analysis was based on data acquired during odd-numbered months. The derived multiple regression predictive formula was then applied to data acquired during even-numbered months, to assess accuracy of prediction. This analysis was performed on the entire study population, Group Dec, but not on Group Inc because the number during the even-numbered months $(\mathrm{n}=36)$ was too small to calculate the $5 \%$ assessment of feasibility. The prediction was evaluated as accurate when less than $5 \%$ of the actual HRscan exceeded the predicted HRscan by $\pm 5 \mathrm{bpm}$; this criterion was based on the fact an error of $\pm 5 \mathrm{bpm}$ will result in inadequate 1-beat scan or unnecessary 2-beat scan when the predicted HR was $70-75 \mathrm{bpm}$. A $p$ value of $<0.05$ was determined as significant.

The accurate formula was applied to the HRrest and HRtest to calculate the estimated HRscan. A theoretical acquisition window based on the predictive formula and percentage of RR interval was determined from the estimated HRscan and was compared with the actual acquisition window. If the actual acquisition window was longer than the theoretical acquisition window, the examination was determined to have an excessive acquisition window. The percentage of examinations with excessive acquisition window in the concerned group was estimated.

Clinical parameters, such as sex, age, weight, height, body mass index, amount of contrast material, speed, $\beta$-blockers used, history of diabetes mellitus, and standard deviation of $\mathrm{HR}$ at rest were compared between the Groups Dec and Inc. The same parameters were also compared between the patients whose HRscan decreased from HRtest vs HRscan increased from HRtest, in Group Dec and Group Inc respectively. For comparison, Student's t test was applied for quantitative parameters and Fisher's exact test was applied for categorical data. The significance level was adjusted by Bonferroni to $0.05 / 10=0.005$.

\section{Results}

The measured HRrest, HRtest, and HRscan are shown in Table 1 and Fig. 2. HRtest significantly decreased by approximately $3 \mathrm{bpm}$ from the HRrest; the HRscan significantly decreased by approximately $1.5 \mathrm{bpm}$ from the HRtest. The average duration between the end of the breath hold instruction and the actual scan was $4.3 \mathrm{~s}$. Bland-Altman analysis revealed statistically significant differences between HRrest and HRtest and HRtest and HRscan in all groups. The behavior of HR in Groups Dec and Inc are shown in Table 2. 
Table 1 Comparison of the HRrest, HRtest, and HRscan among the three groups

\begin{tabular}{|c|c|c|c|c|c|c|c|}
\hline & \multirow[t]{2}{*}{ HRrest (bpm) } & \multirow[t]{2}{*}{ HRtest (bpm) } & \multirow[t]{2}{*}{ HRscan (bpm) } & \multicolumn{2}{|c|}{$\begin{array}{l}\text { HRrest versus } \\
\text { HRtest (bpm) }\end{array}$} & \multicolumn{2}{|c|}{$\begin{array}{l}\text { HRtest versus } \\
\text { HRscan (bpm) }\end{array}$} \\
\hline & & & & Bias & $\begin{array}{l}\text { Limits } \\
\text { of agree- } \\
\text { ment }\end{array}$ & Bias & $\begin{array}{l}\text { Limits } \\
\text { of agree- } \\
\text { ment }\end{array}$ \\
\hline Overall & $68.4 \pm 11.9$ & $65.3 \pm 12$ & $63.7 \pm 11.9$ & $-3.11^{*}$ & $\begin{array}{c}-2.77 \text { to } \\
-3.46\end{array}$ & $-1.60^{*}$ & $\begin{array}{c}-1.24 \text { to } \\
-1.95\end{array}$ \\
\hline $\begin{array}{l}\text { HRtest decreasing } \\
\text { group }\end{array}$ & $68.3 \pm 11.6$ & $64.4 \pm 11.3$ & $62.9 \pm 11.2$ & $-3.81^{*}$ & $\begin{array}{c}-3.48 \text { to } \\
-4.14\end{array}$ & $-1.51^{*}$ & $\begin{array}{c}-1.14 \text { to } \\
-1.88\end{array}$ \\
\hline $\begin{array}{l}\text { HRtest increasing } \\
\text { group }\end{array}$ & $69.9 \pm 14.3$ & $72.7 \pm 14.4$ & $70.4 \pm 15.3$ & $2.75^{*}$ & 2.16 to 3.33 & $-2.33^{*}$ & $\begin{array}{c}-0.95 \text { to } \\
-3.70\end{array}$ \\
\hline
\end{tabular}

$H R$ heart rate, $B P M$ beats per minute

* Statistically significant

The ratios of changes in the HRscan in Groups Dec and Inc were not significantly different from each other $(\mathrm{p}=0.83)$.

The results of multiple regression analysis are shown in Table 3. For the overall study population, the predictive formula based on data during odd-numbered months $(\mathrm{n}=293)$ was calculated as follows:

$$
\text { HRscan }=3.368+0.096 \text { HRtest }+0.823 \text { HRtest }
$$

Applying this formula to the data during even-numberd months $(n=270)$, the actual HRscan was out of the $\pm 5 \mathrm{bpm}$ range in 57 patients (19.5\%), indicating that the formula reached our criteria for accuracy. For the Group Dec, the predictive formula based on data during odd-numbered months $(\mathrm{n}=273)$ was calculated as follows:

$$
\text { HRscan }=3.601+0.113 \text { HRrest }+0.8 \text { HRtest }
$$

Applying this formula to the data during even-numbered month $(\mathrm{n}=232)$, the actual HRscan was out of $\pm 5 \mathrm{bpm}$ range in only four patients (1.5\%), indicating that the formula was likely to be feasible. This formula was applied to Group Dec and the estimated HRscan was calculated; the actual acquisition window was assessed as excessive in 80 patients (14.2\%) (Fig. 3).

No significant difference was observed in clinical parameters between Group Dec and Group Inc, and their subgroups (Table 4).

\section{Discussion}

To the best of our knowledge, this is the first study on a large population of 563 patients that analyzed HR changes during cardiac 320-detector row CT. Our results revealed significant decreases in HR by breath hold and contrast injection. The HR test decreased from HR rest in approximately $90 \%$ of patients, but increased from HRrest in $10 \%$ of patients. HRscan significantly decreased from HRtest, regardless of the changes in HR during breath hold. For Group Dec, it was feasible to predict HRscan from HRrest and HRtest with the formula that we specified, with $14.2 \%$ of the scans having an excessive acquisition window.

The RR interval is influenced by various factors, such as arterial pressure receptors, chemical receptors, cardiac receptors, and stretch receptors in the lungs and thoracic 

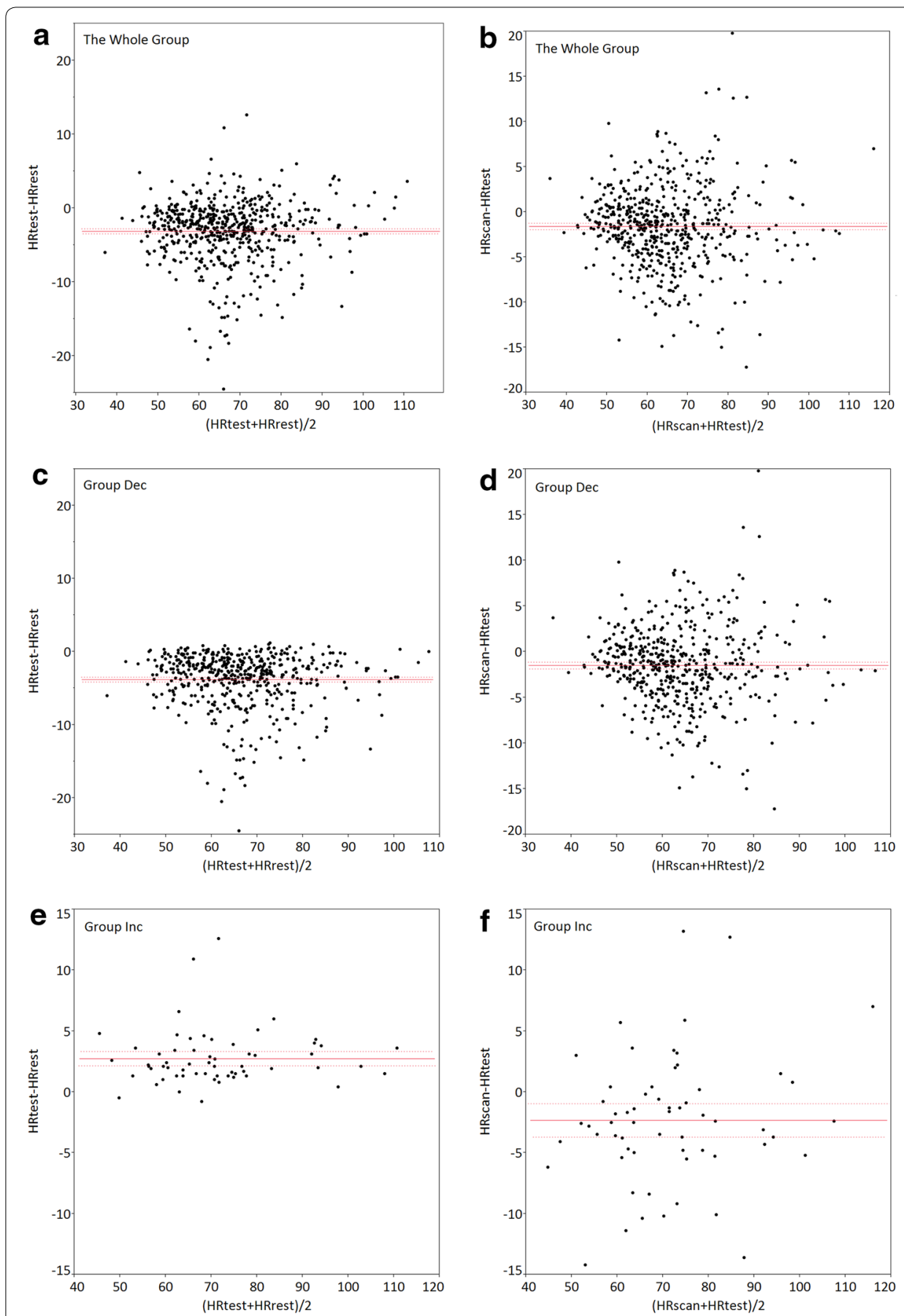

Fig. 2 Bland-Altman plot of HRrest versus HRtest and HRtest versus HRscan in the entire study population $(\mathbf{a}, \mathbf{b})$; In Group Dec (c, d); and in Group Inc $(\mathbf{e}, \mathbf{f})$. The solid grey line indicates bias. The two broken gray lines indicate limits of agreement 
Table 2 Classification of patients according to HRchanges during examination

\begin{tabular}{llll}
\hline & HRtest & & \\
\cline { 2 - 4 } & Decrease from HRrest (= Group Dec) & Increase from HRrest (= Group Inc) & Total \\
\hline HRscan & & & \\
Decrease from HRtest & $388(77.1)$ & $47(78.3)$ & 435 \\
Increase from HRtest & $115(22.9)$ & $13(21.7)$ & 228 \\
Total & 503 & 60 & 563 \\
\hline
\end{tabular}

Data are presented as number (\%)

$H R$ heart rate

Table 3 Results of multiple regression analysis

\begin{tabular}{llllcr}
\hline Population & Factor & Coefficient $(\boldsymbol{\beta})$ & Standard error & t value & p value \\
\hline Overall $(\mathrm{n}=293)$ & HRrest & 0.096 & 0.063 & 1.514 & $0.013^{*}$ \\
& HRrest & 0.823 & 0.063 & 13.05 & $<0.001^{*}$ \\
Group Dec $(\mathrm{n}=273)$ & HRrest & 0.113 & 0.068 & 1.670 & $0.0095^{*}$ \\
& HRrest & 0.800 & 0.069 & 11.58 & $<0.001^{*}$ \\
\hline
\end{tabular}

HR heart rate

*Statistical significance $p<0.05$
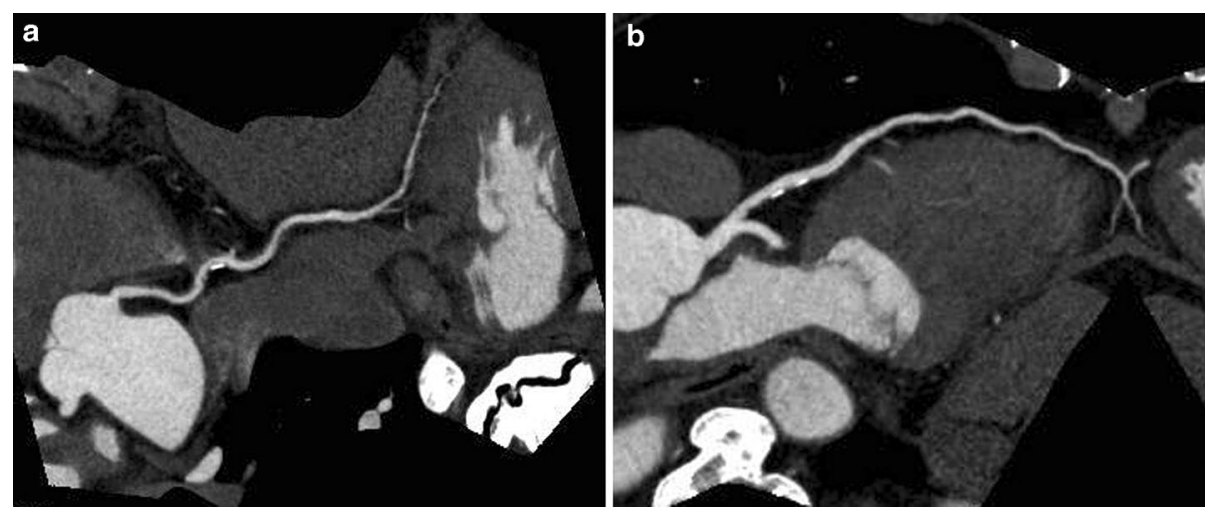

Fig. 3 ECG-gated cardiac CT with curved multi-planar reconstruction in a 68-year-old man with multiple coronary risks. A rest $\mathrm{HR}$ of $=72$ beats per minute was scanned with a narrow acquisition window and effective dose of $1.32 \mathrm{mSv}$ at a HR of $=68$ beats per minute to obtain high-quality images of the RCA (a) and LAD (b). HRrest, HRtest, HRscan were 72, 70, and 68 bpm, respectively. If HR was kept at 72 bpm throughout the examination, it would have been necessary to set a systole-diastole acquisition window (i.e. 30-80 \%). RCA right coronary artery, LAD left anterior descending artery

cavity (Wheeler and Watkins 1973; Horiguchi et al. 2006; Cooke et al. 1998; Clynes 1960; Angelone and Coulter 1964). Respiration is the most influential factor for the RR interval; upon inhalation, a negative intrathoracic pressure increases venous return and $H R$ (Clynes 1960). However, although HR increases for $4 \mathrm{~s}$, it is also known to decrease for $10 \mathrm{~s}$ afterwards; this may explain the behavior of HR during breath hold (Clynes 1960). Although the HRtest and HRscan in the present study were recorded to be approximately $4 \mathrm{~s}$ after the breath hold instruction, patients started holding their breaths after 
Table 4 Comparison of clinical parameters among groups of patients who underwent cardiac CT examinations

\begin{tabular}{|c|c|c|c|c|c|c|c|c|c|}
\hline & \multicolumn{3}{|l|}{ Overall } & \multicolumn{3}{|l|}{ Group Dec } & \multicolumn{3}{|l|}{ Group Inc } \\
\hline & Group Dec & Group Inc & $p$ & HRscan Dec & HRscan Inc & $\mathbf{p}$ & HRscan Dec & HRscan Inc & $\mathbf{p}$ \\
\hline $\operatorname{Sex}(M: F)$ & $284: 219$ & $27: 33$ & 0.15 & 229:160 & $56: 59$ & 0.097 & $19: 28$ & $8: 5$ & 0.25 \\
\hline Age (years) & $65.1 \pm 12.9$ & $63.7 \pm 17.0$ & 0.44 & $65.5 \pm 12.3$ & $63.6 \pm 14.8$ & 0.16 & $66.0 \pm 13.9$ & $55.2 \pm 24.0$ & 0.04 \\
\hline $\begin{array}{l}\text { Body weight } \\
(\mathrm{kg})\end{array}$ & $61.4 \pm 14.5$ & $58.7 \pm 15.0$ & 0.18 & $61.0 \pm 13.3$ & $62.7 \pm 17.8$ & 0.28 & $59.1 \pm 14.5$ & $57.3 \pm 17.4$ & 0.7 \\
\hline $\begin{array}{l}\text { Body height } \\
\text { (m) }\end{array}$ & $1.61 \pm 0.10$ & $1.59 \pm 0.11$ & 0.18 & $1.61 \pm 0.10$ & $1.59 \pm 0.11$ & 0.07 & $1.58 \pm 0.11$ & $1.63 \pm 0.09$ & 0.16 \\
\hline $\begin{array}{l}\text { Body mass } \\
\text { index }\end{array}$ & $23.6 \pm 4.2$ & $23.2 \pm 4.7$ & 0.45 & $23.4 \pm 3.82$ & $24.5 \pm 5.33$ & 0.015 & $23.6 \pm 4.6$ & $21.5 \pm 4.9$ & 0.14 \\
\hline $\begin{array}{l}\text { Contrast } \\
\text { material } \\
(\mathrm{ml})\end{array}$ & $45.8 \pm 10.4$ & $44.2 \pm 10.6$ & 0.26 & $45.5 \pm 10.1$ & $47.1 \pm 11.1$ & 0.16 & $44.8 \pm 11.1$ & $41.2 \pm 8.5$ & 0.28 \\
\hline $\begin{array}{c}\text { Injection } \\
\text { speed } \\
(\mathrm{ml} / \mathrm{s})\end{array}$ & $3.6 \pm 0.7$ & $3.4 \pm 0.7$ & 0.04 & $3.6 \pm 0.7$ & $3.6 \pm 0.8$ & 0.64 & $3.4 \pm 0.6$ & $3.2 \pm 0.8$ & 0.35 \\
\hline $\begin{array}{c}\beta \text { blocker } \\
(-/+)\end{array}$ & $238 / 265$ & $35 / 25$ & 0.16 & 190/199 & $48 / 47$ & 0.8 & $26 / 21$ & $9 / 4$ & 0.45 \\
\hline $\begin{array}{c}\text { Diabetes mel- } \\
\text { litus }(-/+)\end{array}$ & $-336 / 167$ & $44 / 16$ & 0.41 & 258/131 & $78 / 37$ & 0.81 & $34 / 13$ & $10 / 3$ & 0.8 \\
\hline $\begin{array}{l}\text { SD of HR in } \\
\text { rest }\end{array}$ & $1.89 \pm 4.27$ & $2.14 \pm 3.45$ & 0.67 & $1.82 \pm 4.59$ & $2.13 \pm 2.94$ & 0.5 & $1.70 \pm 2.40$ & $3.70 \pm 5.76$ & 0.06 \\
\hline
\end{tabular}

the inhalation instruction that came before the breath hold. Therefore, we consider that breath hold duration was actually longer than $4 \mathrm{~s}$.

Decrease of the HRscan from the HRtest may be partially explained by deep inhalation during breath hold at scanning. One possible explanation for the HRscan being lower than the HRtest is the difference in frequency and depth of respiration, which are known to influence RR interval (Angelone and Coulter 1964). Fast contrast injection may also contribute to decrease in HR, but we could not find the supporting evidence.

The results of previous small-scale studies that determined HRscan decreasd from HRtest have been heterogeneous and controversial. Zhang studied 101 patients who underwent 64-row cardiac CT and concluded that HR decreased by approximately $4 \mathrm{bpm}$ during breath hold, but was same during the scan and at rest (Zhang et al. 2008). Horiguchi analyzed 112 patients who underwent 64-row coronary CT and found that HR during coronary angiogram scan was almost the same as the HR during non-contrast calcium scoring scan obtained with breath hold (Horiguchi et al. 2011). They also found that HR range was wider during coronary angiogram scan than during calcium scoring scan; therefore. HR during coronary angiogram scan may be difficult to predict. Christensen studied 64-row cardiac CT in 60 patients and compare Iopamidol-370 versus Iodixanol-320 (Christensen et al. 2011). They found no significant HR changes between the breath hold HR and scan HR when Iopamidol-370 was used; whereas the scan HR significantly decreased by approximately $2 \mathrm{bpm}$ from breath hold HR when Iodixanol-320 was injected, by about $2 \mathrm{bpm}$. Becker studied 64-row dual-source cardiac CT in 96 patients and compared Iomeprol-400 versus iso-osmolar Iodixanol-320; they concluded that there were no significant HR changes between the calcium scoring scan and coronary angiogram scan (Becker et al. 2011). The results of the present study on 
a large population shows that both breath hold and contrast injection were associated with significant decreases in HR during scanning, at least for 320-row cardiac CT.

The derived predictive formula was feasible for Group Dec and could retrospectively determine the examinations with theoretically excessive acquisition window. As a next step, we would like to prospectively apply this formula on patients with decreased HR during breath hold to predict the HR at scan and to determine the width of acquisition window. Further validation of the formula would be possible by comparing image qualities between experience-based and formula-based cardiac CT scans.

For Group Inc, we could not derive a predictive formula because the number of patients was too small to perform a feasibility study. As shown in Table 2, the HRscan increased from the HRtest in $21.7 \%$ of patients in the Group In. This percentage of patients was prone to scan failure, particularly when HR was $65-75 \mathrm{bpm}$. Therefore, if a patient showed increase in HR during breath hold, it may be better to widen the acquisition window when the rest HR was higher than $65 \mathrm{bpm}$, and to increase the number of scans when the rest HR was higher than $75 \mathrm{bpm}$.

This study had some limitations. We could not analyze variation in HR in a longer span of time because the HRrest was recorded for only $10 \mathrm{~s}$, whereas some of the past pulmonary or abdominal studies recorded the rest HR for 5 min (Chartrand-Lefebvre et al. 2011; Sahani et al. 2007; Romano et al. 2009). This restriction was due to the original setting of the ECG that we used. Another limitation was the likelihood that the timing of starting inhalation and breath hold varied from patient to patient. Many patients started to inhale at the beginning of instructions, but some started after the end of instructions for inhalation, or even after the breath hold instruction.

\section{Conclusions}

The HRtest significantly decrease by approximately $3 \mathrm{bpm}$ from the HRrest in $90 \%$, and the HRscan significantly decrease by approximately $1.5 \mathrm{bpm}$ from the HRtest. Predictive formula for HRscan seems to be accurate and prevent excessive acquisition window for Group Dec patients.

\section{Authors' contributions}

EM participated in the design of the study, performed statistical analysis and drafted the manuscript. NT conceived the study, performed statistical analysis, and drafted the manuscript. KY, KS, MU, AS and RT participated in the acquisition and interpretation of data. MA participated in the design of the study and interpretation of data and drafted the manuscript. Kl and TS collected data. KO participated in the study design and coordination and helped draft the manuscript. All authors read and approved the final manuscript.

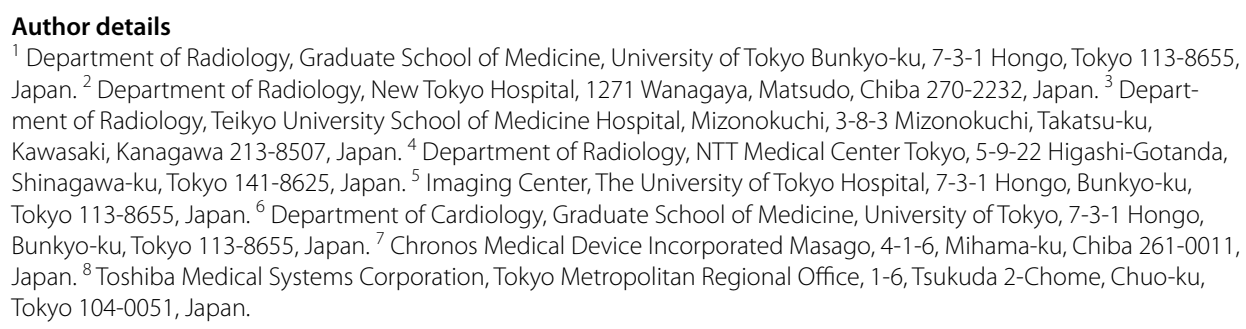

Acknowledgements

The authors would like thank Enago (http://www.enago.jp) for the English language review.

The author Toshiaki Semboku is a regular employee of Chronos Medical Device, Incorporated. The author Rumiko Torigoe is a regular employee of Toshiba Medical Systems Corporation. The other authors declare that they have no competing interests. 
Received: 15 May 2015 Accepted: 28 October 2015

Published online: 12 November 2015

\section{References}

Angelone A, Coulter NA Jr (1964) Respiratory sinus arrhythmia: a frequency dependent phenomenon. J Appl Physiol 19:479-482

Becker CR, Vanzulli A, Fink C et al (2011) Multicenter comparison of high concentration contrast agent iomeprol-400 with iso-osmolar iodixanol-320 contrast enhancement and heart rate variation in coronary dual-source computed tomographic angiography. Invest Radiol 46:457-464

Chartrand-Lefebvre C, White CS, Bhalla S et al (2011) Comparison of the effect of low- and iso-osmolar contrast agents on heart rate during chest CT angiography: results of a prospective randomized multicenter study. Radiology 258:930-937

Christensen JD, Meyer LT, Hurwitz LM et al (2011) Effects of iopamidol-370 versus iodixanol-320 on coronary contrast, branch depiction, and heart rate variability in dual-source coronary MDCT angiography. AJR Am J Roentgenol 197:W445-W451

Clynes M (1960) Computer analysis of reflex control and organization: respiratory sinus arrhythmia. Science 131:300-302

Cooke WH, Cox JF, Diedrich AM et al (1998) Controlled breathing protocols probe human autonomic cardiovascular rhythms. Am J Physiol Heart Circ Physiol 274:709-718

Halliburton SS, Stillman AE, FlohrT et al (2003) Do segmented reconstruction algorithms for cardiac multi-slice computed tomography improve image quality? Herz 28:20-31

Herzog C, Nguyen SA, Savino G et al (2007) Does two-segment image reconstruction at 64-section ct coronary angiography improve image quality and diagnostic accuracy? Radiology 244:121-129

Horiguchi L, Shen Y, Ni Hira et al (2006) Timing on 16-slice scanner and implications for 64-slice cardiac CT: do you start scanning immediately after breath hold? Acad Radiol 13:173-176

Horiguchi J, Yamamoto H, Arie R et al (2011) Is it possible to predict heart rate and range during enhanced cardiac CT scan? J Digital Imaging 24:688-693

Romano L, Grazoli L, Bonomo L et al (2009) Enhancement and safety of iomeprol-400 and iodixanol-320 in patients undergoing abdominal multidetector CT. Br J Radiol 82:204-211

Sahani DV, Soulez G, Chen KM et al (2007) A comparison of the efficacy and safety of iopamidol-370 and iodixanol-320 in patients undergoing multidetector-row computed tomography. Invest Radiol 42:856-861

Tomizawa N, Yamamoto K, Akahane M et al (2013) The feasibility of halfcycle reconstruction in high heart rates in coronary CT angiography using 320-row CT. Int J Cardiovasc Imaging 29:907-911

Wheeler T, Watkins PJ (1973) Cardiac denervation in diabetes. Br Med J 4:584-586

Zhang J, Fletcher JG, Harmsen WS et al (2008) Analysis of heart rate and heart rate variation during cardiac CT examinations. Acad Radiol 15:40-48

\section{Submit your manuscript to a SpringerOpen ${ }^{\circ}$ journal and benefit from:}

- Convenient online submission

Rigorous peer review

- Immediate publication on acceptance

- Open access: articles freely available online

- High visibility within the field

- Retaining the copyright to your article

Submit your next manuscript at $\boldsymbol{s p r i n g e r o p e n . c o m ~}$ 